\title{
Comparative Study on the Extraction and Quantification of Polyphenols from Moringa oleifera Leaves Using Maceration with Pulsed Electric Field (PEF) as Pretreatment and Microwave-Assisted Extraction (MAE)
}

\author{
Sukardi*, Puput Safitri, Hendrix Yulis Setyawan \\ Department of Agro-industrial Technology, Faculty of Agricultural Technology, Universitas Brawijaya, Malang, \\ Indonesia \\ *Corresponding author.Email: sukardi@ub.ac.id
}

\begin{abstract}
Moringa oleifera leaves are rich in nutrients and bioactive compounds such as polyphenols which can be used as an antioxidant. Polyphenols of Moringa leaves can be extracted using conventional and non-conventional methods. This study compared maceration with Pulsed Electric Field (PEF) pretreatment and MAE method on extracting polyphenols from Moringa leaves. The performance of those methods was assessed based on the yield extracts, total polyphenol content (TPC), and antioxidant activity (IC50). The results showed that different methods significantly affected TPC and antioxidant activity. Maceration with PEF pretreatments obtained extracts with the highest TPC value (179.11 mg GAE/g) and antioxidant activity (33.56 ppm). In comparison, the MAE method produced TPC and antioxidant activity values of $22.64 \mathrm{mg}$ GAE/g and $54.59 \mathrm{ppm}$, respectively. The yield extracts did not show differences significantly. Maceration with PEF pretreatment and MAE obtained the yield extract of $12.62 \%$ and $13.16 \%$, respectively. Based on the results, it can be seen that maceration with PEF pretreatment has a better ability to increase TPC and antioxidant activity compared to the MAE method. Maceration with PEF pretreatment can increase TPC up to 7.9 times and antioxidant activity up to 1.6 times.
\end{abstract}

Keywords: Antioxidant activity, Extraction, Maceration, Moringa leaves, Pulsed Electric Field

\section{INTRODUCTION}

Moringa oleifera, commonly called a "magical tree," is a native plant of the Himalayas that grows well in tropical and subtropical regions [1]. The part of this plant that is most often consumed is leaves. Moringa leaves are widely used as a drug for several diseases such as malaria, hypertension, and diabetes [2]. In developing countries, Moringa leaves are commonly used as supplements to treat malnutrition [3] and to improve nutrition in breastfeeding mothers [4]. These uses are related to the nutrients contained in the leaves. Moringa leaves contain vitamins A, vitamin C, Vitamin $\mathrm{B}$, calcium, potassium, iron, and protein [5]. In addition, Moringa leaves are also a source of polyphenol compounds which have many uses for the body [6].

Polyphenols are bioactive compounds that are cardioprotective, antioxidant, anticancer, antiinflammatory, anti-aging, and antimicrobial [7]. Polyphenol compounds primarily found in Moringa leaves are flavonoids and phenolic acids. These 
polyphenol compounds contribute to the antioxidant activity of Moringa leaves which are known to have an inhibitory percentage of $53.3 \%-71.1 \%$ [8].

Polyphenol compounds in moringa leaves can be extracted through several conventional methods. The most used method is maceration due to its simplicity. Moringa leaves are extracted by the maceration method using ethanol, producing the highest total phenolic, total flavonoid, and antioxidant activity compared to other methods [9]. However, maceration has some disadvantages, requiring a large amount of solvent and a long processing time [10]. Therefore, nonconventional methods are needed to effectively and efficiently increase the extraction process's performance.

One of the non-conventional methods is Microwave-Assisted Extraction (MAE), with the principle of using microwave energy to heat the solvents that contact the sample so that destruction occurs in the plant matrix, which facilitates the diffusion process of active substances [11]. MAE method needs a low solvent volume [12], and it can increase the yield of polyphenol compounds [13].

In addition, increasing the extract yield can also be done using pretreatment. One of the pretreatments being developed is Pulsed Electric Field (PEF), with the principle of providing high-intensity electric fields in the form of short pulses to material placed between two electrodes [14]. This pretreatment is useful to increase mass transfer through the membrane [15]. PEF treatment is proven to increase polyphenol compounds [16]. Based on Bouras' study, PEF pretreatment on Norway spruce bark extraction can increase phenolic compounds extraction up to 8 times and antioxidant activity up to 30 times compared to untreated samples [17]. This study aims to compare the ability of the MAE method and maceration with PEF pretreatment in the extraction of polyphenols from Moringa leaves. The performance of each method was assessed based on the calculation of the total phenol compound and antioxidant activity of Moringa leaf extract.

\section{MATERIALS AND METHODS}

\subsection{Materials and Equipment}

The primary material used in this study was Moringa leaves (Moringa oleifera) obtained from Sukun district, Malang city, East Java, Indonesia. The chemicals used were ethanol, distilled water, Folin-Ciocalteau, gallic acid, $\mathrm{Na}_{2} \mathrm{CO}_{3}$, DPPH $0.2 \mathrm{mM}$, and methanol, obtained from the Laboratory of Biochemistry and Food Analysis Universitas Brawijaya, Malang.

Instruments used in this study were PEF generator (Double Output Bipolar-Monopolar), microwave (Electrolux, $2450 \mathrm{MHz}, 800$ watts), blender (Miyako), oven (Memmert UF55), rotary vacuum evaporator (IKA RV 10), hotplate (AREC), UV-Vis spectrophotometer (Thermo Scientific Genesys 10 UV), vortex (Daihan Scientific VM-10), cuvettes, test tubes, and filter paper.

\subsection{Experimental set-up}

In the PEF treatment, fresh Moringa leaves were washed using tap water to remove dirt. Moringa leaves $(100 \mathrm{~g})$ were pre-treated using PEF with a voltage of 1500 Volts, frequency of $1500 \mathrm{~Hz}$, exposure time of 3 seconds with a cathode-anode distance of $10 \mathrm{~cm}$. Treated Moringa leaves were macerated using ethanol with a ratio of $1: 2(\mathrm{w} / \mathrm{v})$ for 5 hours on a hotplate at $50 \pm 5^{\circ} \mathrm{C}$. The solution was filtered using fine filter paper to obtain a macerate. The macerate was concentrated using a rotary vacuum evaporator for 30 minutes at $50^{\circ} \mathrm{C}, 65 \mathrm{rpm}$, and $100 \mathrm{mBar}$. The concentrated extracts were dried using an oven at $50^{\circ} \mathrm{C}$ for 24 hours. The dried extracts were analyzed for total polyphenols compounds and antioxidant activity.

In the MAE treatment, fresh Moringa leaves were washed using tap water to remove dirt. Moringa leaves $(50 \mathrm{~g})$ and distilled water with a ratio of $1: 2(\mathrm{w} / \mathrm{v})$ were blended for 1 minute. Moringa leaf pulp was poured into an erlenmeyer and put in the microwave to be extracted for 2 minutes. The microwave was set with a maximum power of 400 watts. When the extraction process was done, the solution was filtered using fine filter paper. The liquid extract obtained was concentrated using a rotary vacuum evaporator for 60 minutes at $55^{\circ} \mathrm{C}, 65 \mathrm{rpm}$, and $105 \mathrm{mbar}$. The concentrated extracts were dried using the oven at $50^{\circ} \mathrm{C}$ for 24 hours. The dried extracts were analyzed for yield, total polyphenols compounds, and antioxidant activity.

\subsection{Analysis}

The percent yield of Moringa leaves extracts by maceration with PEF and MAE method was calculated by dividing the weight of dried extracts $(\mathrm{g})$ with initial sample weight $(\mathrm{g})$ and multiplying by 100 [18].

Total polyphenol content (TPC) of Moringa leaves extracts were analyzed quantitatively using the Folin- 
Ciocalteau method using UV-Vis spectrophotometer [19]. In short, TPC analysis was started by making a standard curve of gallic acid to obtain a linear regression equation. Dried extracts $(0.01 \mathrm{~g})$ were dissolved in $10 \mathrm{ml}$ of distilled water. $1 \mathrm{ml}$ of solution was diluted with $10 \mathrm{ml}$ of distilled water and used as a sample. $1 \mathrm{~mL}$ of sample, $5 \mathrm{~mL}$ of $10 \%$ Folin-Ciocalteu reagent, and 2 mLof $7.5 \% \mathrm{Na}_{2} \mathrm{CO}_{3}$ were put into test tubes. The solution was homogenized using vortex and then incubated for 30 minutes in dark conditions. The absorbance of the solution was measured at $765 \mathrm{~nm}$. TPC was expressed as milligram of Gallic Acid Equivalent per gram (mg GAE/g) dry weight of the extract.

Antioxidant activity of Moringa leaves extract was analyzed using 2,2-diphenyl-b-picryhidrazyl (DPPH) method [20]. Dried extracts $(0.01 \mathrm{~g})$ were dissolved in $10 \mathrm{ml}$ of distilled water to obtain an aliquot of 1000 ppm. The aliquot was diluted to obtain $25,50,75$, and $100 \mathrm{ppm}$. Samples of each concentration were piped as much as $1 \mathrm{~mL}$ were put into a test tube and mixed with $7 \mathrm{ml}$ of methanol and $2 \mathrm{ml}$ of DPPH $0.2 \mathrm{mM}$. Then, the solution was homogenized using a vortex and incubated for 30 minutes in a dark environment. The control was $8 \mathrm{ml}$ of ethanol and $2 \mathrm{ml}$ of DPPH $0.2 \mathrm{mM}$. The absorbance of the sample and the control was measured at a wavelength of $517 \mathrm{~nm}$. Calculation of antioxidant activity was represented as inhibition concentration, which was calculated based on the absorbance of sample and control. The values of inhibition concentration were plotted on the $x$ and $y$ axes, respectively, to obtain a linear regression equation. Antioxidant activity was expressed as microgram per milliliter $(\boldsymbol{\mu} \mathrm{g} / \mathrm{ml})$ or part per million (ppm).

Each extraction method was done with triplicate measurements and then analyzed to determine the significance of the factor to each parameter. Data were analyzed by Analysis of Variance (ANOVA) using SPSS 16.0 software. The significant level used in this study was $5 \%(\mathrm{p}<0.05)$.

\section{RESULTS AND DISCUSSION}

\subsection{Yield of Moringa Leaves Extracts}

The yield of Moringa leaves extracts by using maceration with PEF and MAE methods was the range of $12.62-13.16 \%$ (Figure 1). The MAE method produced a slightly higher yield of $13.16 \%$, while the PEF method produced a marginally lower yield of $12.62 \%$. However, the value was not significantly different from maceration with the PEF and MAE methods. The ANOVA also showed that the extraction method did not significantly affect the yield of Moringa leaves extracts $(\mathrm{p}>0.05)$.

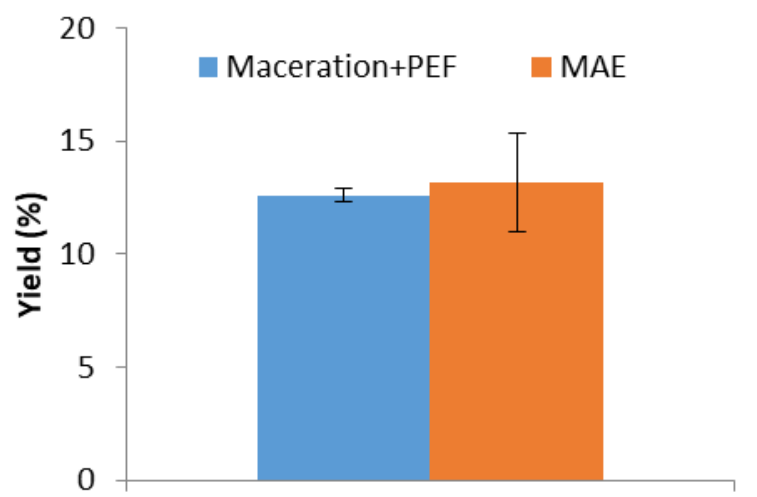

Figure 1 The comparison of yield obtained from PEF and MAE extraction methods. Values represent the means \pm SD of triplicate measurements

\subsection{Total Polyphenol Content (TPC)}

Figure 2 shows that maceration with the PEF method obtains a higher TPC value than MAE. The TPC of Moringa leaves extracts using maceration with $\mathrm{PEF}$ and MAE method was 22.64 to $179.11 \mathrm{mg} \mathrm{GAE} / \mathrm{g}$. The PEF method produced a TPC of $179.11 \mathrm{mg}$ GAE/g, while the MAE method produced $22.64 \mathrm{mg}$ GAE/g. In addition, ANOVA showed that the extraction method had a significant effect on the TPC of Moringa leaves extracts $(\mathrm{p}<0.05)$.

\subsection{Antioxidant Activity (IC $\left.C_{50}\right)$}

Figure 3 shows that maceration with the PEF method obtains higher antioxidant activity than MAE. $\mathrm{IC}_{50}$ of Moringa leaves extracted using PEF and MAE method was found in the range of 33.56 to $54.59 \mathrm{ppm}$. The lower $\mathrm{IC}_{50}$ showed the higher antioxidant activity because it showed a better ability to scavenge DPPH as free radicals [21]. The antioxidant activity of 33.56 
ppm was obtained by maceration with the PEF method, higher than that of $54.59 \mathrm{ppm}$ obtained by the MAE method. In addition, the ANOVA showed that the extraction method had a significant effect on the antioxidant activity of Moringa leaves extracts ( $p$ $<0.05)$.

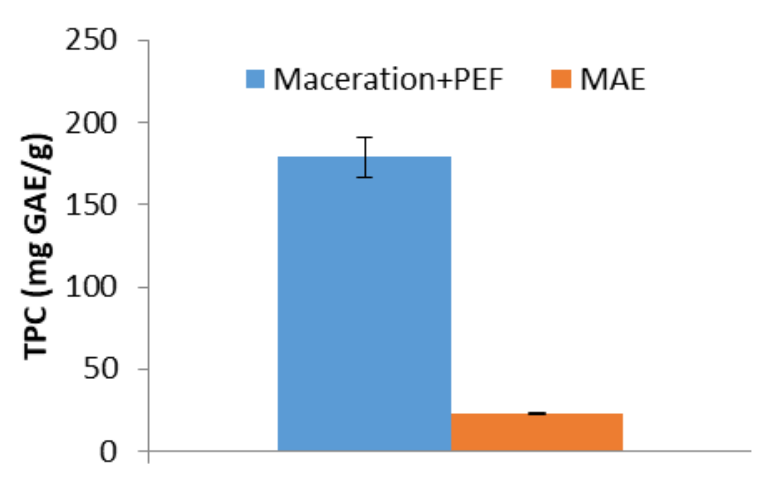

Figure 2 The comparison of TPC value obtained from $\mathrm{PEF}$ and MAE extraction methods. Values represent the means \pm SD of triplicate measurements

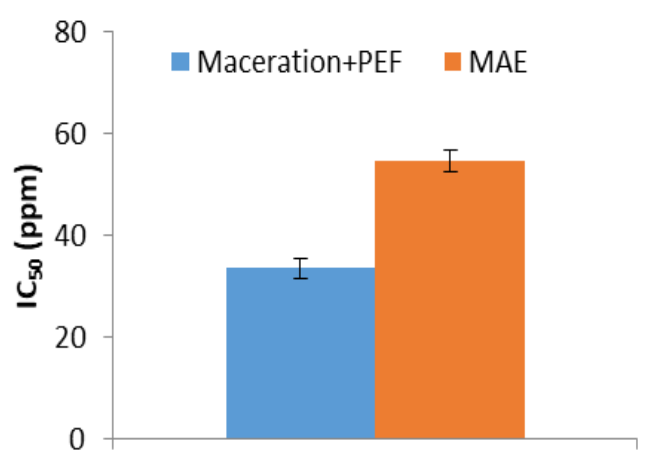

Figure 3 The comparison of $\mathrm{IC}_{50}$ value obtained from PEF and MAE extraction methods. Values represent the means \pm SD of triplicate measurements

\subsection{Discussion}

This study was conducted to compare the ability of maceration with the PEF and MAE method in the extraction of polyphenols from Moringa leaves. It can be seen that maceration with PEF pretreatment is the better method to extract polyphenols of Moringa leaves because the TPC and antioxidant activity value are higher than the MAE method.

The average yield of Moringa leaf extract by maceration with PEF and MAE method respectively was $12.62 \%$ and $13.16 \%$, which did not significantly differ. The two extraction methods used different types of solvents so that the ability to evaporate during the drying process is also other. Ethanol evaporates faster than distilled water because the boiling point of ethanol is lower than distilled water [22]. However, the yield was calculated after the drying process in which limited remaining solvents were present in the extract.

TPC value of Moringa leaf extracts by maceration method with PEF of $179.11 \mathrm{mg} \mathrm{GAE} / \mathrm{g}$ was 7.9 times higher than that of MAE method. It was consistent with a study on Borago officinalis leaves extraction, which proves that PEF treatment can increase the yield of polyphenol extraction by up to $6.6 \%$ [23]. Comparative studies of the PEF and MAE methods have also been carried out on Moringa leaves extraction, showing PEF could increase TPC by 1.1 times [24]. PEF can increase polyphenol compounds because PEF treatment causes the formation of pores in cell membranes that facilitate the release of intracellular substances [25].

The highest antioxidant activity (33.56 ppm) was obtained by maceration with the PEF method, 1.6 times higher than that of the MAE method. It was consistent with research on Borago officinalis leaves extraction, proving that PEF treatment can increase antioxidant activity up to $13.7 \% .23$ Comparative studies of the PEF and MAE methods have also been carried out on Moringa leaves extraction that showed PEF could increase antioxidant activity up to 1.2 times [24].

\section{CONCLUSION}

This study showed the maceration performance with the PEF and MAE methods on extracting polyphenol compounds from Moringa leaves. The maceration with PEF pretreatment produced extracts with the higher total polyphenol content and antioxidant activity of $33.56 \mathrm{ppm}$ and $179.11 \mathrm{mg} \mathrm{GAE} / \mathrm{g}$, respectively, with an extract yield of $12.62 \%$. Maceration with PEF pretreatment can increase the recovery of polyphenol up to 7.9 times and antioxidant activity up to 1.6 times. 
This study showed the potential of PEF pretreatment in increasing yield and recovery of total polyphenol content and antioxidant activity of Moringa leaves extracts. Further study needs to be done focusing on optimization of extraction using maceration with PEF pretreatment characteristics, such as electric field strength, frequency, and exposure time.

\section{REFERENCES}

[1] R.J. Wright, K.S. Lee, H.I. Hyacinth, J.M. Hibbert, M.E. Reid, A.O. Wheatley, H.N. Asemota, An investigation of the antioxidant capacity in extracts from Moringa oleifera plants grown in Jamaica, Plants (Basel, Switzerland), vol. 6 , no. 4, 2017. DOI: $10.3390 /$ plants 6040048

[2] A. Leone, A. Spada, A. Battezzati, A. Schiraldi, J. Aristil, S. Bertoli, Cultivation, genetic, ethnopharmacology, phytochemistry and pharmacology of Moringa oleifera leaves: an overview, International Journal of molecular sciences, vol. 16, no. 6, 2015, pp. 12791-12835. DOI: $10.3390 / \mathrm{ijms} 160612791$

[3] J.O. Popoola, O.O. Obembe, Local knowledge, use pattern and geographical distribution of Moringa oleifera Lam. (Moringaceae) in Nigeria, Journal of Ethnopharmacology, vol. 150, no. 2, 2013, pp. 682-691. DOI: 10.1016/j.jep.2013.09.043

[4] Z. Zakaria, V. Hadju, Suryani, B. Bahar, The effect of moringa leaf extract in breastfeeding mothers against anemia status and breast milk iron content, International Journal of Sciences: Basic and Applied Research, vol. 24, 2015, pp. 321-329.

[5] R. Paliwal, V. Sharma, . P., A Review on horse radish tree (Moringa oleifera): a multipurpose tree with high economic and commercial importance, Asian Journal of Biotechnology, vol. 3, no. 4, 2011, pp. 317-328. DOI: 10.3923/AJBKR.2011.317.328

[6] M. Vergara-Jimenez, M.M. Almatrafi, M.L. Fernandez, Bioactive components in Moringa oleifera leaves protect against chronic disease, antioxidants (Basel, Switzerland), vol. 6, no. 4, 2017. DOI: 10.3390 /antiox6040091

[7] J.S. T, G.S. V, S. Priyanka, W. Lafayette, Polyphenol grape extract using Pulsed Electric Field, 2018, pp. 1-7.

[8] P. Nobossé, E.N. Fombang, C.M.F. Mbofung, Effects of age and extraction solvent on phytochemical content and antioxidant activity of fresh Moringa oleifera L. leaves, Food science \& nutrition, vol. 6 , no. 8, 2018, pp. 2188-2198. DOI: $10.1002 / \mathrm{fsn} 3.783$

[9] B. Vongsak, P. Sithisarn, S. Mangmool, S. Thongpraditchote, Y. Wongkrajang, W. Gritsanapan, Maximizing total phenolics, total flavonoids contents and antioxidant activity of Moringa oleifera leaf extract by the appropriate extraction method, Industrial Crops and Products, vol. 44, 2013, pp. 566-571. DOI: 10.1016/J.INDCROP.2012.09.021

[10] Q.-W. Zhang, L.-G. Lin, W.-C. Ye, Techniques for extraction and isolation of natural products: a comprehensive review, Chinese medicine, vol. 13, 2018, p. 20. DOI: 10.1186/s13020-0180177-x

[11] C.H. Chan, R. Yusoff, G.C. Ngoh, F.W.L. Kung, Microwave-assisted extractions of active ingredients from plants, Journal of Chromatography A, vol. 1218, no. 37, 2011, pp. 6213-6225.

DOI:

10.1016/J.CHROMA.2011.07.040

[12] P. Garcia-Salas, A. Morales-Soto, A. SeguraCarretero, A. Fernández-Gutiérrez, Phenoliccompound-extraction systems for fruit and vegetable samples, Molecules (Basel, Switzerland), vol. 15 , no. 12,2010 , pp. 8813 8826. DOI: $10.3390 /$ molecules 15128813

[13] M. Bouras, M. Chadni, F.J. Barba, N. Grimi, O. Bals, E. Vorobiev, Optimization of microwaveassisted extraction of polyphenols from Quercus bark, Industrial Crops and Products, vol. 77, 2015, pp. 590-601. DOI: 10.1016/J.INDCROP.2015.09.018

[14] S. Asavasanti, S. Ersus, W. Ristenpart, P. 
Stroeve, D.M. Barrett, Critical electric field strengths of onion tissues treated by pulsed electric fields, Journal of food science, vol. 75, no. 7, 2010, pp. E433-43. DOI: 10.1111/j.17503841.2010.01768.x

[15] L.-G. Yan, L. He, J. Xi, High intensity pulsed electric field as an innovative technique for extraction of bioactive compounds-A review, Critical Reviews in Food Science and Nutrition, vol. 57, no. 13, 2017, pp. 2877-2888. DOI: 10.1080/10408398.2015.1077193

[16] N. Boussetta, E. Vorobiev, L.H. Le, A. CordinFalcimaigne, J.L. Lanoisellé, Application of electrical treatments in alcoholic solvent for polyphenols extraction from grape seeds, LWT Food Science and Technology, vol. 46, no. 1, 2012, pp. 127-134. DOI: 10.1016/J.LWT.2011.10.016

[17] M. Bouras, N. Grimi, O. Bals, E. Vorobiev, Impact of pulsed electric fields on polyphenols extraction from Norway spruce bark, Industrial Crops and Products, vol. 80, 2016, pp. 50-58. DOI: $10.1016 /$ J.INDCROP.2015.10.051

[18] M.N. Safdar, T. Kausar, S. Jabbar, A. Mumtaz, K. Ahad, A.A. Saddozai, Extraction and quantification of polyphenols from kinnow (Citrus reticulate L.) peel using ultrasound and maceration techniques, Journal of food and drug analysis, vol. 25 , no. 3 , 2017, pp. 488-500. DOI: 10.1016/j.jfda.2016.07.010

[19] Z. Liu, E. Esveld, J.-P. Vincken, M.E. Bruins, Pulsed Electric Field as an alternative pretreatment for drying to enhance polyphenol extraction from fresh tea leaves, Food and Bioprocess Technology, vol. 12, no. 1, 2019, pp. 183-192. DOI: 10.1007/s11947-018-2199-x
[20] R.N. Lailatul, Sukardi, D.B.S. Diyah, W.H. Ari, Effect of frequency and duration of pulsed electric field pre-treatment on antioxidant compounds extraction of dry areca nut (Areca catechu), Biotika, vol. 5, 2017, pp. 69-75.

[21] A.V. Badarinath, K.M. Rao, C.C. Madhusudhana, A review on in-vitro antioxidant methods: comparisons, correlations and considerations, 2010.

[22] Q.A. Acton, Propanols--Advances in Research and Application ScholarlyBrief, 2013.

[23] F.J. Segovia, E. Luengo, J.J. Corral-Pérez, J. Raso, M.P. Almajano, Improvements in the aqueous extraction of polyphenols from borage (Borago officinalis L.) leaves by pulsed electric fields: Pulsed electric fields (PEF) applications, Industrial Crops and Products, vol. 65, 2015, pp. 390-396.

DOI:

10.1016/J.INDCROP.2014.11.010

[24] G.P. 't Lam, P.R. Postma, D.A. Fernandes, R.A.H. Timmermans, M.H. Vermuë, M.J. Barbosa, M.H.M. Eppink, R.H. Wijffels, G. Olivieri, Pulsed electric field for protein release of the microalgae Chlorella vulgaris and Neochloris oleoabundans, Algal Research, vol. 24, 2017, pp. 181-187. DOI: 10.1016/J.ALGAL.2017.03.024

[25] E. Bozinou, I. Karageorgou, G. Batra, V. G. Dourtoglou, S. I. Lalas, Pulsed Electric field extraction and antioxidant activity determination of Moringa oleifera dry leaves: a comparative study with other extraction techniques, Beverages, vol. 5, no. 1, 2019. DOI: $10.3390 /$ beverages 5010008 